\title{
Pengaruh Kepemilikan Institusi, Kualitas Audit, Profitabilitas, Dan Leverage Terhadap Post-IPO Survival
}

\author{
Adhi Christian Ciuyono \\ Program Studi Magister Akuntansi Fakultas Ekonomi \\ Universitas Tarumanagara, Jakarta \\ adhi.ciuyono@gmail.com
}

\begin{abstract}
Investors, practitioners, and regulators in Indonesia seek to understand what factors that determine a company survival in the stock market. This research is to analyze whether institutional ownership, audit quality, profitability and leverage have positive significant effect on post-IPO survival. The statistical method used to analyze the data in this research is multiple linear regression and the subject of this research is consumer goods public companies in Indonesia over the period 2010-2016. The result of this research shows that institutional ownership and profitability have positive significant effect on post-IPO survival, while audit quality and leverage have no significant effect on post-IPO survival.
\end{abstract}

Keywords: Post-IPO Survival, Institutional Ownership, Audit Quality, Profitability, Leverage.

\begin{abstract}
Abstrak: Para investor, praktisi, regulator dan pembuat kebijakan di Indonesia mencoba mencari tahu faktor-faktor apa saja yang membuat perusahaan dapat survive di pasar modal. Penelitian ini mengkaji apakah kepemilikan institusi, kualitas audit, profitabilitas, dan leverage berpengaruh signifikan positif terhadap post-IPO survival. Metode statistik yang digunakan dalam penelitian ini adalah regresi linier berganda dengan subyek penelitian adalah perusahaan publik sektor barang konsumsi di Indonesia tahun 2010-2016. Hasil penelitian menunjukkan bahwa kepemilikan institusi dan profitabilitas memiliki pengaruh yang signifikan positif terhadap post-IPO survival sementara itu kualitas audit dan leverage tidak memiliki pengaruh yang signifikan terhadap post-IPO survival.
\end{abstract}

Kata-kata kunci: Post-IPO Survival, Kepemilikan Institusi, Kualitas Audit, Profitabilitas, Leverage.

\section{Latar Belakang}

Initial Public Offering (IPO) merupakan salah satu cara bagi perusahaan untuk mendapatkan tambahan modal secara cepat dan dengan biaya yang lebih kecil dibandingkan dengan private markets untuk melakukan ekspansi usaha dan menjalankan rencana strategis perusahaan. Dengan melakukan IPO maka perusahaan memiliki kewajiban yang lebih besar karena berkaitan dengan banyak pemegang kepentingan termasuk di dalamnya adalah para investor dan regulator pasar modal (Otoritas Jasa Keuangan). Investor tentunya memiliki harapan agar perusahaan yang dibeli lewat pasar modal lewat kepemilikan saham dapat terus berkembang dan memberikan imbal hasil yang tinggi baik berupa deviden maupun kenaikan harga saham (capital gain). Namun, tidak semua perusahaan yang melakukan IPO dapat memuaskan para investor dan memiliki performa perusahaan yang baik. Ada banyak faktor yang mempengaruhi performa perusahaan setelah IPO yang akan berdampak pada mampu tidaknya perusahaan bertahan setelah IPO (post-IPO survival). Bagi regulator, post-IPO survival merupakan salah-satu tolak ukur mengenai tingkat keberhasilan dari peraturan yang dibuat terhadap perusahaan yang akan melakukan IPO.

Kepemilikan institusi merupakan bagian lain dari corporate governance, karena institusi mempunyai sumber daya, kemampuan dan kesempatan untuk memantau dan mendisiplinkan manajer agar lebih terfokus pada nilai perusahaan (Siregar \& Utama, 2005). Di dalam Cornett et al. (2006) terdapat adanya bukti yang menyatakan bahwa tindakan pengawasan yang dilakukan oleh sebuah perusahaan dan pihak investor institusional dapat membatasi perilaku manajer. Dengan demikian, tindakan pengawasan perusahaan yang dilakukan oleh pihak institutional owners dapat mendorong manajer untuk lebih memfokuskan perhatiannya terhadap performa perusahaan. Oleh karena itu, tingkat kepemilikan institusi akan berpengaruh terhadap post-IPO survival.

Kualitas audit yang baik memungkinkan semakin kecil terjadinya manipulasi laporan keuangan sehinga laporan keuangan akan menyajikan informasi yang mengambarkan kondisi sebenarnya dari perusahaan tersebut. Investor di pasar modal akan cenderung memilih perusahaan yang laporan 
keuangannya diaudit oleh kantor akuntan yang memiliki reputasi kualitas audit yang baik. Sementara itu, perusahaan dengan kualitas audit yang buruk akan membuat investor menjadi tidak percaya dengan informasi laporan keuangannya sehingga perusahaan akan kesulitan mencari pendanaan yang akan berpengaruh terhadap performa perusahaan sehingga akan berdampak pada post-IPO survival.

Tingkat profitabilitas mencerminkan kemampuan perusahaan dalam memperoleh keuntungan dan tingkat efisiensi atas penggunaan aset perusahaan serta merupakan salah satu aspek yang penting sebagai acuan oleh investor atau pemilik dalam menilai kinerja suatu perusahaan. Profitabilitas merupakan faktor yang dapat mempengaruhi post-IPO survival. Leverage menggambarkan penggunaan aset dan dana pinjaman perusahaan yang mengeluarkan beban tetap yaitu beban bunga. Perusahaan yang dipercaya menggunakan utang dapat mendukung kegiatan usahanya. Apabila hasil kegiatan usahanya positif akan menghasilkan tambahan pendapatan. Sebaliknya, apabila hasil kegiatan usahanya negatip maka perusahaan dapat mengalami kesulitan keuangan yang dapat mempengaruhi post-IPO survival.

Sudah ada banyak penelitian serupa yang dilakukan di berbagai negara diantaranya adalah di Afrika Selatan oleh Neneh \& Smit (2014), di Taiwan oleh Woody et al. (2013) dan Chen \& Chen (2008), di Italia oleh Cirillo et al. (2017), di Inggris oleh Espenlaub et al. (2015), dan bahkan dengan cakupan global di 32 negara oleh Espenlaub et al. (2016). Perlu dilakukan penelitian di Indonesia guna membuktikan terjadinya konsep tersebut pada kondisi pasar saham yang berbeda-beda.

Woody et al. (2013) menemukan hasil bahwa venture capital yang merupakan salah satu bentuk kepemilikan institusi berpengaruh positif terhadap financial stability yang merupakan faktor penentu postIPO survival, sedangkan Espenlaub et al. (2015) menemukan bahwa kepemilikan institusi berupa cornerstone investor tidak berpengaruh signifikan terhadap post-IPO survival. Penelitian oleh Neneh \& Smit (2014) menghasilkan ratio profitabilitas berpengaruh positif terhadap post-IPO survival. Espenlaub et al. (2016) menemukan bahwa pre-IPO ROA berpengaruh signifikan positif terhadap post-IPO survival.

Chen \& Chen (2008) menemukan leverage signifikan positif mempengaruhi IPO long-run performance. Sementara itu Chancharat et al. (2008) menemukan low leverage signifikan mempengaruhi post-IPO survival.

Masalah yang terjadi di dalam post-IPO survival berakibat pada delisting di Indonesia. Sebagian besar perusahaan yang didelisting merupakan involuntary delisting yang disebabkan oleh kondisi perusahaan yang mengalami masalah finansial maupun hukum juga ketidakpatuhan terhadap peraturan pasar modal. Padahal ada banyak pihak yang memiliki kepentingan terhadap kelangsungan perusahaan agar dapat terus survive setelah melakukan IPO terutama para investor dan regulator pasar modal.

Ruang lingkup penelitian ini dibatasi hanya pada perusahan publik sektor barang konsumsi yang terdaftar di Bursa Efek Indonesia. Variabel-variabel yang diteliti adalah kepemilikan institusi, kualitas audit, profitabilitas, leverage, dan post-IPO survival pada tahun 2010-2016.

Perumusan Masalah. (1) Apakah kepemilikan institusi berpengaruh signifikan positif terhadap post-IPO survival?; (2) Apakah kualitas audit berpengaruh signifikan positif terhadap post-IPO survival?; (3) Apakah profitabilitas berpengaruh signifikan positif terhadap post-IPO survival?; (4) Apakah leverage berpengaruh signifikan positif terhadap post-IPO survival?

\section{Metodologi}

Populasi. Populasi dalam penelitian ini adalah perusahaan manufaktur sektor barang konsumsi yang terdaftar di Bursa Efek Indonesia pada tahun 2010-2016. Jumlah perusahaan manufaktur sektor barang konsumsi yang terdaftar di Bursa Efek Indonesia sejak tahun 2010 - 2016 sebanyak 33 - 40 perusahaan. Selama periode tersebut ada tiga perusahaan yang mengalami delisting sehingga tidak dimasukkan sebagai sampel.

Metode Pemilihan Sampel. Metode pemilihan sampel yang digunakan dalam penelitian ini adalah metode tidak acak, sedangkan teknik pemilihan sampel yang digunakan adalah teknik purposive sampling. Jumlah sampel perusahaan yang digunakan dalam penelitian ini berjumlah dua ratus lima puluh sembilan sampel data perusahaan.

Teknik Analisa Data. Tehnik analisis data menggunakan analisis regresi berganda guna membuktikan hipotesis. 
1. Pengujian hipotesis menggunakan analisis regresi linier berganda.

2. Model regresi yang digunakan dalam penelitian ini adalah:

1) $P I S=\mathrm{a}_{1}+\mathrm{b}_{1} I N S+\mathrm{b}_{2} A Q U A L+\mathrm{b}_{3} P R O F+\mathrm{b}_{4} L E V+\mathrm{e}$

PIS : Post-IPO Survival

$\mathrm{a}_{1} \quad$ : Nilai intercept atau konstanta,

INS : Kepemilikan Institusi

AQUAL : Kualitas Audit

$P R O F$ : Profitabilitas

LEV : Leverage

$b_{1}-b_{4}$ : Koefisien regresi kepemilikan institusi, kualitas audit, profitabilitas, leverage

$e \quad$ : Kekeliruan atau residu atau error

3. Uji ketepatan model: dengan Koefisien determinasi $\left(\mathrm{R}^{2}\right)$

4. Uji Hipotesis 1 - Hipotesis 4 dilakukan dengan Uji t dengan asumsi tingkat signifikansi $95 \%$.

Analisis Statistik Deskriptif.

Tabel 1

Hasil Analisis Statistik Deskriptif

\begin{tabular}{|l|r|r|r|r|r|}
\hline & \multicolumn{1}{|c|}{$\mathrm{N}$} & \multicolumn{1}{c|}{ Minimum } & \multicolumn{1}{c|}{ Maximum } & \multicolumn{1}{c|}{ Mean } & \multicolumn{1}{c|}{ Std. Deviation } \\
\hline INS & 237 & 0.224784 & 1.000000 & 0.76607478 & 0.179027529 \\
\hline AQUAL & 184 & 0.001176 & 0.479807 & 0.09122146 & 0.086148375 \\
\hline PROF & 215 & 0.000933 & 0.950314 & 0.18146894 & 0.217823459 \\
\hline LEV & 242 & 0.069175 & 1.248573 & 0.41472789 & 0.199716133 \\
\hline SIZE & 247 & 25.17 & 32.15 & 28.2087 & 1.60253 \\
\hline PIS & 234 & 12.00 & 420.00 & 224.1538 & 99.51803 \\
\hline Valid N (listwise) & 158 & & & & \\
\hline
\end{tabular}

Sumber: hasil pengolahan data menggunakan IBM SPSS Statistics 24, 2018

Variabel kepemilikan institusi (INS) dengan jumlah data valid (N) sebanyak 237 mempunyai nilai minimum sebesar 0,224784 (PT Wismilak International Tbk) dan nilai maksimum sebesar 1,000000 (PT Martina Berto Tbk), nilai rata-rata sebesar 0,76607478 dan standar deviasi sebesar 0,179027529.

Variabel kualitas audit (AQUAL) dengan jumlah data valid $(\mathrm{N})$ sebanyak 184 mempunyai nilai minimum sebesar 0,001176 (PT Chitose Internasional Tbk) dan nilai maksimum sebesar 0,479807 (PT Wilmar Cahaya Indonesia Tbk), nilai rata-rata sebesar 0,09122146 dan standar deviasi sebesar 0,086148375.

Variabel profitabilitas (PROF) dengan jumlah data valid $(\mathrm{N})$ sebanyak 215 mempunyai nilai minimum sebesar 0,000933 (PT Indofarma (Persero) Tbk) dan nilai maksimum sebesar 0.950314 (PT Tempo Scan Pacific Tbk), nilai rata-rata sebesar 0,18146894 dan standar deviasi sebesar 0,217823459.

Variabel leverage ( $L E V)$ dengan jumlah data valid $(\mathrm{N})$ sebanyak 242 mempunyai nilai minimum sebesar 0,069175 (PT Sido Muncul Tbk) dan nilai maksimum sebesar 1,248573 (PT Bentoel Internasional Investama Tbk), nilai rata-rata sebesar 0,41472789 dan standar deviasi sebesar 0,199716133.

Variabel ukuran perusahaan (SIZE) dengan jumlah data valid (N) sebanyak 247 mempunyai nilai minimum sebesar 25,17 (PT Kedaung Indah Can Tbk) dan nilai maksimum sebesar 32,15 (PT Indofood Sukses Makmur Tbk), nilai rata-rata sebesar 28,2087 dan standar deviasi sebesar 1,60253.

Variabel post-IPO survival (PIS) dengan jumlah data valid $(\mathrm{N})$ sebanyak 234 mempunyai nilai minimum sebesar 12,00 (PT Indofood CBP Sukses Makmur Tbk) dan nilai maksimum sebesar 420 (PT Unilever Indonesia Tbk), nilai rata-rata sebesar 224,1538 dan standar deviasi sebesar 99,51803. 
Tabel 2

Hasil Analisis Regresi Linear Berganda

\begin{tabular}{|c|c|c|c|c|c|c|}
\hline \multirow{2}{*}{\multicolumn{2}{|c|}{ Model }} & \multicolumn{2}{|c|}{$\begin{array}{c}\text { Unstandardized } \\
\text { Coefficients }\end{array}$} & \multirow{2}{*}{$\begin{array}{c}\text { Standardized } \\
\text { Coefficients } \\
\text { Beta }\end{array}$} & \multirow[b]{2}{*}{$\mathrm{t}$} & \multirow[b]{2}{*}{ Sig. } \\
\hline & & B & Std. Error & & & \\
\hline \multirow[t]{5}{*}{1} & (Constant) & 117.438 & 35.855 & & 3.275 & 0.001 \\
\hline & INS & 85.015 & 42.299 & 0.160 & 2.010 & 0.046 \\
\hline & AQUAL & 140.977 & 84.611 & 0.127 & 1.666 & 0.098 \\
\hline & PROF & 98.842 & 34.391 & 0.235 & 2.874 & 0.005 \\
\hline & LEV & 55.141 & 44.678 & 0.096 & 1.234 & 0.219 \\
\hline
\end{tabular}

a. Dependent Variable: PIS

b. Weighted Least Squares Regression - Weighted by SIZE

Sumber: hasil pengolahan data menggunakan IBM SPSS Statistics 24, 2018

Berdasarkan hasil pengujian analisis regresi, dibuatlah model persamaan regresi seperti berikut: $P I S=117,438+85,015 I N S+140,977 A Q U A L+98,842 P R O F+55,141 L E V$

Dari persamaan regresi di atas, dapat disimpulkan bahwa nilai konstanta sebesar 117,438 menyatakan bahwa jika variabel kepemilikan institusi, kualitas audit, profitabilitas dan leverage diberi nilai nol, maka variabel post-IPO survival akan menghasilkan nilai sebesar 117,438. Hal ini menandakan bahwa masih terdapat faktor-faktor selain kepemilikan institusi, kualitas audit, profitabilitas dan leverage yang dapat mempengaruhi perubahan nilai post-IPO survival pada perusahaan manufaktur sektor barang konsumsi yang terdaftar di BEI periode 2010-2016.

Koefisien regresi INS adalah sebesar 85,015. Hal ini menunjukkan apabila INS meningkat sebesar 1 satuan, dan AQUAL, PROF serta $L E V$ adalah tetap, maka post-IPO survival akan mengalami peningkatan sebesar 85,015 satuan.

Koefisien regresi $A Q U A L$ adalah sebesar 140,977. Hal ini menunjukkan apabila $A Q U A L$ meningkat sebesar 1 satuan, dan INS, PROF serta $L E V$ adalah tetap, maka post-IPO survival akan mengalami peningkatan sebesar 140,977 satuan.

Koefisien regresi $P R O F$ adalah sebesar 98,842. Hal ini menunjukkan apabila PROF meningkat sebesar 1 satuan, dan INS, AQUAL serta $L E V$ adalah tetap, maka post-IPO survival akan mengalami peningkatan sebesar 98,842 satuan.

Koefisien regresi $L E V$ adalah sebesar 55,141. Hal ini menunjukkan apabila $L E V$ meningkat sebesar 1 satuan, dan INS, AQUAL serta PROF adalah tetap, maka post-IPO survival akan mengalami peningkatan sebesar 55,141 satuan.

\section{Analisa Uji Koefisien Determinasi $\left(\mathbf{R}^{2}\right)$.}

Tabel 3

Hasil Uji Koefisien Determinasi $\left(\mathrm{R}^{2}\right)$ Model Summary

\begin{tabular}{|l|l|r|r|r|}
\hline Model & R & R Square & Adjusted R Square & Std. Error of the Estimate \\
\hline 1 & $.361^{\mathrm{a}}$ & 0.130 & 0.107 & 490.05063 \\
\hline
\end{tabular}

a. Predictors: (Constant), LEV, INS, AQUAL, PROF

Sumber: hasil pengolahan data menggunakan IBM SPSS Statistics 24, 2018

Berdasarkan hasil pengolahan data pada tabel 7 diatas, diketahui nilai adjusted $R$ square adalah sebesar 0,107. Jika dijadikan sebagai koefisien determinasi angka tersebut menjadi 0,107 dikalikan dengan 100\% sama dengan $10,70 \%$. Angka tersebut mempunyai pengertian bahwa sebesar 10,70\% post-IPO survival yang terjadi dapat dijelaskan dengan menggunakan variabel independen kepemilikan institusi, kualitas audit, profitabilitas dan leverage. Dengan demikian dapat dikatakan bahwa variabel independen kepemilikan 
institusi, kualitas audit, profitabilitas dan leverage mempengaruhi variabel dependen post-IPO survival sebesar $10,70 \%$. Sedangkan sisanya, yaitu $89,30 \%$ harus dijelaskan oleh faktor-faktor penyebab lainnya diluar model regresi ini.

\section{Analisa Uji Signifikansi Simultan (Uji F).}

Ho: Tidak terdapat pengaruh yang signifikan positif antara kepemilikan institusi, kualitas audit, profitabilitas dan leverage terhadap post-IPO survival secara simultan.

Ha: Terdapat pengaruh yang signifikan positif antara kepemilikan institusi, kualitas audit, profitabilitas dan leverage terhadap post-IPO survival secara simultan.

Hasil uji $\mathrm{F}$ dapat dilihat pada tabel 8 di bawah ini

Tabel 4

Hasil Uji Signifikan Simultan (Uji F) ANOVA ${ }^{a, b}$

\begin{tabular}{|l|l|r|r|r|r|r|}
\hline \multicolumn{2}{|l|}{ Model } & Sum of Squares & df & Mean Square & \multicolumn{1}{c|}{ F } & \multicolumn{1}{c|}{ Sig. } \\
\hline \multirow{3}{*}{1} & Regression & 5498024.566 & 4 & 1374506.141 & 5.724 & $.000^{\mathrm{c}}$ \\
\cline { 2 - 8 } & Residual & 36742892.090 & 153 & 240149.622 & & \\
\cline { 2 - 8 } & Total & 42240916.655 & 157 & & & \\
\hline
\end{tabular}

a. Dependent Variable: PIS

b. Weighted Least Squares Regression - Weighted by SIZE

c. Predictors: (Constant), LEV, INS, AQUAL, PROF

Sumber: hasil pengolahan data menggunakan IBM SPSS Statistics 24, 2018

Berdasarkan hasil pengujian signifikan simultan diperoleh nilai signifikansi sebesar 0,000 nilai ini lebih kecil dari 0,05. Oleh sebab itu, dapat disimpulkan bahwa kepemilikan institusi, kualitas audit, profitabilitas dan leverage memiliki pengaruh signifikan terhadap post-IPO survival dan model ini masuk dalam kriteria cocok atau fit.

\section{Analisa Uji Statistik t.}

Tabel 5

Hasil Uji Signifikan Parameter Individual (Uji t) dengan Variabel Kontrol

\begin{tabular}{|c|c|c|c|c|c|c|}
\hline \multirow{2}{*}{\multicolumn{2}{|c|}{ Model }} & \multicolumn{2}{|c|}{$\begin{array}{c}\text { Unstandardized } \\
\text { Coefficients }\end{array}$} & \multirow{2}{*}{$\begin{array}{c}\text { Standardized } \\
\text { Coefficients }\end{array}$} & \multirow[b]{2}{*}{$\mathrm{t}$} & \multirow[b]{2}{*}{ Sig. } \\
\hline & & B & Std. Error & & & \\
\hline \multirow[t]{5}{*}{1} & (Constant) & 117.438 & 35.855 & & 3.275 & 0.001 \\
\hline & INS & 85.015 & 42.299 & 0.160 & 2.010 & 0.046 \\
\hline & AQUAL & 140.977 & 84.611 & 0.127 & 1.666 & 0.098 \\
\hline & PROF & 98.842 & 34.391 & 0.235 & 2.874 & 0.005 \\
\hline & LEV & 55.141 & 44.678 & 0.096 & 1.234 & 0.219 \\
\hline
\end{tabular}

a. Dependent Variable: PIS

b. Weighted Least Squares Regression - Weighted by SIZE

Sumber: hasil pengolahan data menggunakan IBM SPSS Statistics 24, 2018

Berdasarkan Tabel 6 persamaan regresi linear sederhana antara variabel kepemilikan institusi dan post-IPO survival variabel INS memiliki nilai signifikansi (Sig.) sebesar 0,046. < 0,05 bahwa kepemilikan institusi signifikan positif mempengaruhi post-IPO survival pada perusahaan manufaktur sektor barang konsumsi yang terdaftar di BEI periode 2010-2016.

Kualitas audit dengan Sig. 0,098>0,05 tidak signifikan positip mempengaruhi post-IPO survival pada perusahaan manufaktur sektor barang konsumsi yang terdaftar di BEI periode 2010-2016. 
Profitabilitas dengan nilai signifikansi (Sig.) $0,005<0.05$ signifikan positif mempengaruhi post-IPO survival pada perusahaan manufaktur sektor barang konsumsi yang terdaftar di BEI periode 2010-2016.

Leverage dengan nilai signifikansi (Sig.) 0,219>0,05 tidak signifikan positip mempengaruhi post-IPO survival pada perusahaan manufaktur sektor barang konsumsi yang terdaftar di BEI periode 2010-2016.

\section{Perbandingan Hasil Tanpa Variabel Kontrol (TVK) dengan Hasil yang ada Variabel Kontrol (VK).}

Tabel 6

Perbandingan Hasil Tanpa Variabel Kontrol dengan yang ada Variabel Kontrol

\begin{tabular}{|l|c|c|}
\hline Parameter & TVK & VK \\
\hline R square & 0,135 & 0,130 \\
\hline Koefesien Regresi INS & 93,229 & 85,015 \\
\hline Koefesien Regresi $A Q U A L$ & 143,660 & 140,977 \\
\hline Koefesien Regresi $P R O F$ & 97,429 & 98,842 \\
\hline Koefesien Regresi $L E V$ & 48,307 & 55,141 \\
\hline
\end{tabular}

Sumber: hasil pengolahan data menggunakan IBM SPSS Statistics 24, 2018

Dari hasil yang ditampilkan diatas, terlihat bahwa koefisien determinasi ( $\mathrm{R}$ square) tanpa variabel kontrol (ukuran perusahaan) sebesar 0,135 sedangkan koefisien determinasi dengan variabel kontrol sebesar 0,130. Dengan adanya variabel kontrol koefisien determinasi menjadi lebih kecil.

Koefisien regresi variabel kepemilikan institusi tanpa variabel kontrol sebesar 93,229 sedangkan dengan variabel kontrol sebesar 85,015. Dengan adanya variabel kontrol koefisien regresi kepemilikan institusi menjadi lebih kecil.

Koefisien regresi variabel kualitas audit tanpa variabel kontrol sebesar 143,660 sedangkan dengan variabel kontrol sebesar 140,977. Dengan adanya variabel kontrol koefisien regresi kualitas audit menjadi lebih kecil. Koefisien regresi variabel profitabilitas tanpa variabel kontrol sebesar 97,429 sedangkan dengan variabel kontrol sebesar 98,842. Dengan adanya variabel kontrol koefisien regresi profitabilitas menjadi lebih besar.

Koefisien regresi variabel leverage tanpa variabel kontrol sebesar 48,307 sedangkan dengan variabel kontrol sebesar 55,141. Dengan adanya variabel kontrol koefisien regresi leverage menjadi lebih besar.

Dari hasil analisis diatas, dapat disimpulkan bahwa dengan adanya variabel kontrol yakni SIZE maka terdapat dua variabel independen yang mengalami kenaikan koefisien regresi yakni profitabilitas dan leverage. Hal ini menunjukkan pengaruh variabel independen (profitabilitas dan leverage) ke variabel dependen dengan adanya variabel kontrol menjadi semakin besar.

\section{Pembahasan}

Setelah pengujian diatas, maka dalam penelitian ini, terdapat empat hipotesis yang diuji, yaitu kepemilikan institusi berpengaruh secara signifikan positif terhadap post-IPO survival, kualitas audit berpengaruh secara signifikan positif terhadap post-IPO survival, profitabilitas berpengaruh secara signifikan positif terhadap post-IPO survival, dan leverage berpengaruh secara signifikan positif terhadap post-IPO survival.

a. Kepemilikan institusi signifikan positif mempengaruhi post-IPO survival.

Hasil ini sejalan dengan penelitian Espenlaub et al. (2015) yang menyatakan kepemilikan institusi berbentuk strategic investor berpengaruh signifikan terhadap IPO survival. Demikian juga dengan penelitian Woody et al. (2013) yang menyatakan bahwa venture capital berpengaruh positif terhadap financial stability. Hasil ini tidak sejalan dengan penelitian Espenlaub et al. (2015) yang menyatakan cornerstone investor tidak berpengaruh signifikan terhadap IPO survival. Dari pengujian diatas dapat disimpulkan bahwa dengan adanya kepemilikan institusi yang semakin besar dalam suatu perusahaan maka investor menjadi lebih percaya kepada kemampuan perusahaan untuk memiliki performa yang lebih baik sehingga akan berpengaruh pada survival perusahaan. Hal ini disebabkan semakin besarnya kepemilikan institusi maka pengawasan terhadap manajemen perusahaan menjadi lebih ketat dibandingkan apabila diawasi oleh individu perorangan sehingga kepercayaan investor menjadi meningkat. 
b. Kualitas audit tidak signifikan positip mempengaruhi post-IPO survival.

Hasil ini tidak sejalan dengan penelitian Jain and Martin (2005) yang menyatakan kualitas audit berpengaruh signifikan terhadap post-IPO performance. Dari pengujian diatas dapat disimpulkan bahwa kualitas audit yang tercermin dari hasil laporan audit yang dikeluarkan oleh pihak auditor tidak terlalu berpengaruh terhadap kepercayaan pihak investor terhadap kemampuan kinerja perusahaan kedepannya untuk terus dapat survive.

c. Profitabilitas signifikan positif mempengaruhi post-IPO survival.

Hasil ini sejalan dengan penelitian Espenlaub et al. (2016) yang menyatakan profitabilitas berpengaruh signifikan terhadap IPO survival. Demikian juga dengan penelitian Neneh and Smit (2014) yang menyatakan bahwa profitability ratio berpengaruh signifikan terhadap IPO survival. Dari pengujian diatas dapat disimpulkan bahwa dengan semakin tinggi profitabilitas suatu perusahaan maka investor menjadi semakin percaya kepada kemampuan perusahaan untuk memiliki performa yang lebih baik sehingga akan berpengaruh pada survival perusahaan.

d. Leverage tidak signifikan positip mempengaruhi post-IPO survival.

Hasil ini tidak sejalan dengan penelitian Chen and Chen (2008) yang menyatakan leverage berpengaruh signifikan terhadap IPO long-run performance. Dari pengujian diatas dapat disimpulkan bahwa makin tingginya leverage yang dimiliki perusahaan tidak terlalu berpengaruh terhadap kepercayaan pihak investor terhadap kemampuan kinerja perusahaan kedepannya untuk terus dapat survive. Kemampuan perusahaan untuk mengelola leverage yang tinggi agar dapat menghasilkan keuntungan operasi yang tinggi tidak terlalu berdampak pada kepercayaan investor terhadap kinerja perusahaan.

\section{Penutup}

Saran. Bagi penelitian selanjutnya, penggunaan sampel data lebih luas dan mencakup sektor lainnya seperti pertambangan, properti dan keuangan sehingga hasil yang diperoleh dapat lebih menggambarkan kondisi yang general. Variabel independen dapat ditambahkan variabel independen lain yang diperkirakan akan mempengaruhi secara signifikan positif terhadap post-IPO survival. Keterbatasan lainnya adalah penggunaan discretionary accruals sebagai proxy kualitas audit. Seperti halnya penelitian-penelitian yang menggunakan proxy yang sama, kualitas laporan keuangan yang dilaporkan tidak dapat dipisahkan dari kualitas audit. Dalam penelitian ini earning quality tidak dapat diobservasi secara langsung melainkan dengan menggunakan estimasi perhitungan discretionary accruals dengan menggunakan Modified Jones Model.

\section{REFERENSI}

Aji, D. Y., \& Mita, A. F. (2010). Pengaruh Profitabilitas, Risiko Keuangan, Nilai Perusahaan, dan Struktur Kepemilikan Terhadap Praktek Perataan Laba: Studi Empiris Perusahaan Manufaktur Yang Tardaftar di BEI. Simposium Nasional Akuntansi XIII.

Aritonang, L. R. (2007). Riset Pemasaran. Jakarta: Ghalia Indonesia.

Asthana, S., \& Bonne, J. (2012). Abnormal Audit Fee and Audit Quality. Auditing: A Journal of Practice \& Theory, vol.31, no. 3, 1-2.

Azlina N. (2010). Analisis Faktor yang Mempengaruhi Manajemen Laba (Studi Pada Perusahaan yang Terdaftar di BEI). Universitas Riau.

Balsam, S., Krishnan, J., \& Yang, J. S. (2003). Auditor Industry Specialization and Earnings Quality. Journal of Practice and Theory, 71-97.

Becker, C.L., Defond, M.L., Jiambalvo, J., \& Subramanyam, K.R. (1998). The Effect of Audit Quality on Earnings Management. Contemporary Accounting Research, vol.15, no. 1, 1-24.

Chancharat, N., Krishnamurti, C., \& Tian, G.G. (2008). When the Going Gets Tough: Board Capital and Survival of New Economy IPO Firms. The $21^{\text {st }}$ Australasian Finance and Banking Conference, 15921622.

Chen, A. \& Chen, L. W. (2008). Leverage, Liquidity and IPO Long Run Performance: Evidence from Taiwan IPO Markets. International Journal of Accounting \& Information Management, 18(1): 31-38. 
Chen, C.Y., Lin, C.J., \& Lin, Y.C. (2008). Audit Partner Tenure, Audit Firm Tenure, and Discretionary Accruals: Does Long Auditor Tenure Impair Earning Quality? Contemporary Accounting Research, vol. 25 , no. $2,415-445$.

Cirillo, A., Mussolino, D., Romano, M., \& Vigano, R. (2017). A Complicated Relationship: Family Involvement in the Top Management Team and Post-IPO Survival. Journal of Family Business Strategy, 8: 42-56.

Cornett, M. M., Markus, A. J., Saunders A., \& Tehranian, H. (2006). Earnings Management, Corporate Governance, and True Financial Performance. http://papers.ssrn.com/.

Dechow, P. M., R. G. Sloan, \& A. P. Sweeney. (1995). Causes and Consequences of Earnings Manipulation: An Analysis of Firm Subject to Enforcement Actions by the SEC. Contemporary Accounting Research, 13(1): 1-36.

Espenlaub, S., Goyal, A., \& Mohamed, A. (2016). Impact of Legal Institutions on IPO Survival: A Global Perspective. Journal of Financial Stability, 25: 98-112

Espenlaub, S., Khurshed, A., Mohamed, A., \& Saadouni, B. (2015). The Role of Cornerstone and Strategic Investors in IPO Survival. Journal of Corporate Finance, 41: 139-155.

Ghozali, I. (2011). Aplikasi Analisis Multivariate dengan Program IBM SPSS 19. Semarang: Badan Penerbit Universitas Diponegoro.

Jain, B., \& Martin, C. (2005). The Association between Audit Quality and Post-IPO Performance: A Survival Analysis Approach. Review of Accounting and Finance, 4(4): 50-75.

Jogiyanto. (2007). Teori Portofolio dan Analisa Investasi. Edisi Keenam. Cetakan Pertama. Yogyakarta: PT BPFE Yogyakarta.

Koh, K., Rajgopal, S., \& Srinivasan, S. (2013). Non-Audit Services and Financial Reporting Quality: Evidence from 1978-1980. Review of Accounting Studies, vol. 18, no. 1, 1-33.

Lawrence, A., Minutti-Meza, M., \& P. Zhang (2011). Can Big 4 versus Non-Big 4 Differences in AuditQuality Proxies Be Attributed to Client Characteristics? The Accounting Review, vol. 86, no. 1, 259286.

Neneh, N. B., \& Smit, V. A. (2014). Determinants of IPO Survival on the Johannesburg Securities Exchange. Risk Governance \& Control: Financial Markets \& Institutions, 4(3).

Nizarul, A. M, Hapsari, T., \& Purwanti, L. (2007). Pengaruh Kompetensi dan Independensi terhadap Kualitas Auditor dengan Etika Auditor sebagai Variabel Moderasi. Simposium Nasional Akuntansi X.

Rachmawati \& Triatmoko, H. (2007). Analisis Faktor-Faktor yang Mempengaruhi Kualitas Laba dan Nilai Perusahaan. Simposium Nasional Akuntansi X.

Ramadhan, A. (2008). Pengaruh Financial Leverage Terhadap Return on Equity (ROE) dan Earning Per Share (EPS) Pada Perusahaan Pertambangan Logam dan Mineral BEI. Skripsi, Jember : Fakultas Ekonomi Universitas Jember.

Riyanto, B. (2011). Dasar-Dasar Pembelajaran Perusahaan. Edisi 4. Yogyakarta: BPFE.

Riohi-Belkaoui, A. (2004). Accounting Theory. Jakarta: Salemba Empat.

Sanjaya, P. S. (2008). Auditor Eksternal, Komite Audit, dan Manajemen Laba. Jurnal Riset Akuntansi Indonesia, 11(1): 97-116.

Sartono, A. (2012). Manajemen Keuangan: Teori dan Aplikasi. Edisi 4. Yogyakarta: BPFE.

Siregar, S. V., \& Utama, S. (2005). Pengaruh Struktur Kepemilikan, Ukuran Perusahaan, dan Praktek Corporate Governance Terhadap Pengelolaan Laba (Earnings Management). Simposium Nasional Akuntansi VIII.

Siregar, S. V., \& Utama, S. (2008). Type of earnings management and the effect of ownership structure, firm size, and corporate governance practice: Evidence from Indonesia. The International Journal of Accounting, 43(1): 1-26.

Sugiarto. (2009). Struktur Modal, Struktur Kepemilikan Perusahaan, Permasalahan Keagenan dan Informasi Asimetri.Yogyakarta: Graha Ilmu.

Supranto, J. (2009). Statistik: Teori dan Aplikasi Jilid II. Jakarta: Erlangga.

Sulistyanto, S. (2008). Manajemen Laba: Teori dan Empiris. Jakarta: PT. Gramedia. 
Svanstrom, T. (2013). Non-Audit Services and Audit Quality: Evidence from Private Firms. European Accounting Review, vol.22, no. 2, 337-3666.

Tandelilin, E. (2010). Portofolio dan Investasi Teori dan Aplikasi Edisi pertama. Yogyakarta: Kanisius

Ujiyantho. Arief, M., \& Pramuka, B. A. (2007). Mekanisme Corporate Governance, Manajemen Laba dan Kinerja Perusahaan. Simposium Nasional Akuntansi X.

Woody, M. L., Chia-Chi L., \& Wang, H. (2013). Venture Capital, Corporate Finance, and Financial Stability of IPO Firms. Emerging Market Review, 18: 19-33.

Yang, R., Xia, K., \& Wen, H. (2016). Venture capital, finance leverage and enterprise performance. Procedia Computer Science, 91: 114-121. 